REVUE DE L'INSTITUT FRANÇAIS D'HISTOIRE EN ALLEMAGNE

\section{Revue de l'IFHA}

Revue de l'Institut français d'histoire en Allemagne

$1 \mid 2009$

IFHA 1

\title{
Ménestrel : portail francophone de référence en études médiévales, et partenaire de l'IFHA
}

\section{Mathieu Olivier}

\section{(2) OpenEdition}

\section{Journals}

Édition électronique

URL : http://journals.openedition.org/ifha/340

DOI : $10.4000 /$ ifha. 340

ISSN : 2198-8943

\section{Éditeur}

IFRA - Institut franco-allemand (sciences historiques et sociales)

\section{Édition imprimée}

Date de publication : 30 septembre 2009

Pagination : 113-116

ISSN : 2190-0078

\section{Référence électronique}

Mathieu Olivier, «Ménestrel : portail francophone de référence en études médiévales, et partenaire de

I'IFHA », Revue de l'IFHA [En ligne], 1 | 2009, mis en ligne le 07 février 2013, consulté le 21 avril 2019.

URL : http://journals.openedition.org/ifha/340 ; DOI : 10.4000/ifha.340

Ce document a été généré automatiquement le 21 avril 2019

(CIFHA 


\title{
Ménestrel : portail francophone de référence en études médiévales, et partenaire de l'IFHA
}

\author{
Mathieu Olivier
}

1 Est-il encore besoin de présenter le portail Ménestrel, plus important portail médiévistique francophone à vocation généraliste ? ${ }^{1}$ La réponse est positive, ne serait-ce que parce que l'outil a fait peau neuve ces deux ou trois dernières années, proposant un nombre de pages en constante et rapide augmentation.

2 L'acte de naissance du réseau Ménestrel remonte à 1997, alors que la médiévistique en ligne n'en était encore qu'à ses premiers balbutiements. Sa création est le fruit de la collaboration d'un petit groupe de médiévistes français engagés précocement dans l'exploration du potentiel des nouvelles technologies informatiques pour les études médiévales et leur diffusion, autour notamment de la revue Le Médiéviste et l'Ordinateur. Si l'équipe s'est aujourd'hui très largement renouvelée, et certaines priorités ont été redéfinies, la double ambition initiale du portail Ménestrel n'a pas varié. Il a, d'une part, vocation à contribuer au développement et à la publicité des ressources et travaux francophones pour l'étude du Moyen Âge. Il se propose, d'autre part, d'offrir gratuitement un répertoire critique de ressources disponibles dans les domaines les plus variés des études médiévales. L'une des originalités du projet Ménestrel par comparaison avec d'autres portails médiévistiques en ligne réside dans la diversité du public visé. S'il s'adresse en effet en priorité aux chercheurs eux-mêmes, le portail vise également les étudiants des différents cycles et les amateurs avertis. Il bénéficie depuis de nombreuses années du soutien de plusieurs piliers des études médiévales dans l'aire francophone, à commencer par la Société des Historiens Médiévistes de l'Enseignement Supérieur Public (SHMESP), et collabore étroitement avec d'autres portails médiévistiques (Reti Medievali ${ }^{2}$, pour ne prendre qu'un exemple).

3 Fruit de la mue réalisée ces dernières années, la nouvelle mouture de Ménestrel s'organise autour de quatre rubriques principales. Lieux et Acteurs de la recherche propose un tour 
d'horizon des études médiévales et de leur architecture institutionnelle pays par pays. Rédigées selon une grille d'exposition uniformisée, vingt-neuf notices par pays sont actuellement disponibles. L'ambition première est d'arriver à couvrir la totalité des pays européens. Si une belle "percée » en direction de l'Europe centrale et baltique est à enregistrer dans l'année qui vient de s'écouler (mise en ligne des notices Estonie, Lettonie, Finlande), quelques importantes taches blanches demeurent encore (Espagne et Portugal notamment). À terme, la rubrique a bien entendu vocation à s'ouvrir aux études médiévales menées hors d'Europe. La récente publication de la notice Australie, et celle, toute neuve à l'heure où sont écrites ces lignes, de la notice Chili représentent un premier jalon de cette extension programmée.

4 Les utilisateurs désireux d'explorer les ressources proposées par le net à partir d'entrées thématiques se tourneront avec profit vers la rubrique Répertoire de l'internet. Vingt-sept thèmes sont actuellement en ligne, «d'alimentation» à «théâtre médiéval». Nécessairement pointilliste, parce que reflet des centres d'intérêts des contributeurs de Ménestrel, cette revue critique des outils en ligne voit également son contenu s'enrichir à bon rythme. Là encore, ce n'est qu'un début. Coordonnée par deux conservatrices spécialisées en histoire médiévale, la rubrique Le Moyen Âge en bibliothèque privilégie l'approche géographique. L'objectif premier est de décrire rapidement les collections médiévales conservées dans les principales bibliothèques françaises et étrangères. S'y ajoute une seconde ambition: celle de cartographier à l'usage des chercheurs l'accessibilité des bases de données et autres ressources électroniques payantes. La quatrième et dernière rubrique principale - intitulée Collections Ménestrel - donne pleinement corps à la vocation de relais des travaux savants revendiquée par le portail. Y prennent place en effet, dans différentes sous-rubriques (Bibliographies, Catalogue de manuscrits...) les fruits de travaux récents ou en cours de grande ampleur. Sous le titre De l'usage de..., cette même rubrique héberge également depuis peu une série de mises au point sur certains termes et concepts clés de l'histoire médiévale. Récemment lancée, cette nouvelle entreprise ne présente encore que quelques notices (« sources », « genre », « espace »); la liste des entrées à paraitre, d'« image » à "magie » en passant par " Église », « salaire » ou " régressivité », confiées aux meilleurs spécialistes, laisse augurer du profit que l'on pourra tirer à plus ou moins court terme de cette nouvelle sousrubrique en devenir.

$5 \quad$ L'équipe des rédacteurs de Ménestrel apporte un soin tout particulier au suivi éditorial des notices déjà mises en ligne. Celles-ci font en général l'objet de deux à trois mises à jour substantielles par an. Un rapide examen révèle que très rares sont les notices à ne pas avoir été actualisées depuis le début de l'année 2009. Au cœur du projet initial du portail, l'étendard de la francophonie est, de plus en plus, un authentique défi dans le contexte actuel. Si le projet Ménestrel suscite en général le plus grand intérêt des collègues étrangers amenés à le découvrir, les possibilités de collaboration active se heurtent bien souvent à l'obstacle de la langue. La traduction de pages à partir de l'anglais ou d'autres langues confronte l'équipe des rédacteurs à un surcroit de travail difficilement gérable et nuit mécaniquement à la souplesse et à la réactivité du portail. Actuellement, seules certaines pages sont également disponibles dans une version anglaise. Dans la plupart des cas, notamment au sein de la rubrique Lieux et acteurs, il s'agit des notices directement rédigées dans cette langue par les contributeurs étrangers, et traduites en français dans un second temps. 
Depuis plusieurs années, la MHFA était étroitement associée au travail de Ménestrel. Audelà de collaborations plus ponctuelles, l'habitude s'est prise de confier ès qualités aux médiévistes de la Mission la charge de deux notices en particulier : celle sur les études médiévales en Allemagne dans la rubrique Lieux et Acteurs, celle sur l'Allemagne médiévale dans le Répertoire de l'internet. L'expertise des membres de la Mission ne s'arrêtait pas là. Dans le passé le plus récent, les membres de la MHFA ont apporté, par leurs contacts scientifiques, une contribution importante à l'intégration dans l'équipe éditoriale de contributeurs ressortissants et/ou spécialistes des pays d'Europe centrale et orientale. En cela, le partenariat avec Ménestrel est un exemple de mise à profit des compétences et de l'expérience spécifiques des membres de la MHFA à destination d'un vaste public via l'outil informatique. L'institut français d'histoire en Allemagne prolongera ce partenariat réussi.

\section{NOTES}

1. Adresse du site : http://www.menestrel.fr/

2. Adresse du site : http://www.retimedievali.it/

\section{AUTEUR}

\section{MATHIEU OLIVIER}

Mathieu Olivier a été boursier d'aide à la recherche à la MHFA de septembre 2007 à août 2009. Il est depuis le $1^{\mathrm{er}}$ septembre 2009 professeur d'histoire-géographie en section « Abibac » au Lycée Dumont d'Urville à Toulon. 